Short communication

\title{
Validation of a geographic information system model for mapping the risk of fasciolosis in cattle and buffaloes in Cambodia
}

\author{
S. Tum ${ }^{\text {a, M.L. Puotinen }}{ }^{\text {b,* }}$, L.F. Skerratt ${ }^{\text {c }}$, B. Chan ${ }^{\text {a }}$, S. Sothoeun ${ }^{\text {a }}$ \\ ${ }^{a}$ Department of Animal Production and Health, 74 Monivong Boulivard, Sangkat Wat Phnom, Khan Daun Penh, Phnom Penh, Cambodia \\ ${ }^{\mathrm{b}}$ GeoQuEST Research Centre, School of Earth and Environmental Sciences, University of Wollongong, Wollongong, NSW 2522, Australia \\ ${ }^{\mathrm{c}}$ School of Veterinary and Biomedical Sciences, James Cook University, Townsville 4811, Australia
}

Received 26 May 2006; received in revised form 17 August 2006; accepted 24 August 2006

\begin{abstract}
Maps showing gradations of risk of fasciolosis due to Fasciola gigantica in Cambodia were produced using geographic information systems (GIS) technology in conjunction with determinants of fasciolosis. A comparison between levels of risk predicted by the maps and field measurements of prevalence in 11 provinces $(n=1406)$ showed general agreement, which suggested the epidemiological determinants and weightings used to produce the maps were appropriate. However, due to logistical constraints, prevalence was measured at the provincial level and animals were not randomly sampled (and thus were unlikely to be representative of variability within provinces). To address this, additional field work was carried out to measure prevalence in more detail - faecal samples were collected from a randomly selected set of animals in four districts across a representative province for areas predicted to be at high risk $(n=311)$, moderate risk $(n=268)$ and no risk $(n=262)$. As with the original field survey, the results show general agreement between prevalence and risk predicted by the maps, with the best fit found for areas predicted to be at high risk.
\end{abstract}

(C) 2006 Elsevier B.V. All rights reserved.

Keywords: Fasciola gigantica; Fasciolosis; Geographic information systems; Control methods; Trematoda; Cambodia

Tropical fasciolosis caused by infection with Fasciola gigantica occurs in most humid tropical regions of the world. Cattle and buffaloes are the main hosts but other domestic animals and humans are also susceptible. Losses are mainly due to reduced meat production and draught power and lower fertility in infected animals (Spithill et al., 1999). The loss from an estimated $10 \%$ prevalence in cattle and buffaloes in the Kingdom of Cambodia was approximately US\$ 17,020,000 in 2001 (Department of Animal Production and Health, Phnom Penh, 2001). Nevertheless, control

\footnotetext{
* Corresponding author. Tel.: +61 2 42213589; fax: +61242214250 .

E-mail address: marji@uow.edu.au (M.L. Puotinen).
}

is not commonly practiced as most Cambodian farmers have minimal knowledge of fasciolosis. Furthermore, areas where the disease is most important, within which extension programs for control should logically be focused, have not been defined. Collection of prevalence data to enable such areas to be mapped would be costly and cumbersome. A more cost effective alternative is the use of predictive models using geographic information systems (GIS) technology in conjunction with determinants of fasciolosis.

A number of epidemiological studies have identified determinants of fasciolosis caused by $F$. gigantica (Tembely et al., 1988; Malone, 1994; Roberts and Suhardono, 1996; Malone and Yilma, 1999; Spithill et al., 1999; Suhardono and Copeman, 2000). The risk of infection is influenced by the number and distribution 
Table 1

Results of faecal examination from different provinces in 2001/2002 and predicted risk of fasciolosis from the GIS model developed by Tum et al. (2004) generalised by province and adjusted for the known sensitivity of the technique as per Anderson et al. (1999)

\begin{tabular}{llll}
\hline Province & $\begin{array}{l}\text { Sample } \\
\text { size }\end{array}$ & $\begin{array}{l}\text { Percent } \\
\text { positive }(\%)\end{array}$ & $\begin{array}{l}\text { Predicted } \\
\text { risk }\end{array}$ \\
\hline Kandal & 192 & 85.2 & High \\
Kracheh & 119 & 20.1 & Moderate \\
Takeo & 150 & 10.9 & High \\
Kg. Speu & 100 & 7.5 & Moderate \\
Kg. Cham & 94 & 6.3 & Moderate \\
Pursat & 97 & 6.2 & Moderate \\
Battambang & 82 & 5.4 & Moderate \\
Kg. Thom & 102 & 4.4 & Moderate \\
Kg. Chnang & 184 & 3.3 & High \\
Prey Veng & 125 & 0.2 & Moderate \\
Svay Rieng & 161 & 0.0 & High \\
\hline
\end{tabular}

of animals, especially cattle and buffaloes, the presence of infected snails, and grazing management which allows animals to access herbage or water containing metacercariae. Determinants can include all factors that affect the above such as the availability and suitability of habitats for the aquatic molluscan intermediate hosts of $F$. gigantica. A relatively simple mathematical model was developed to map the areas of risk of fasciolosis in Cambodia. The model was constructed using GIS from individual data layers representing district boundaries, rivers, inundated areas, elevation, slope, agricultural land uses and cattle and buffalo density (Tum et al., 2004). A limited field survey was conducted in Cambodia in December 2001 and January 2002 to test the model. Faecal samples were collected opportunistically from 1406 cattle and buffaloes in 11 provinces, and analysed using a modified version of the Balivet egg count technique (Table 1). In general, the measured prevalence of fasciolosis was in accord with the risk predicted by the model in 7 of the 11 provinces, notable exceptions being in Prey Veng and Svay Rieng provinces where the prevalence was much lower than predicted. A likely explanation is that the distribution of animals and the use of the land within provinces were not uniform spatially and seasonally, as implied by the model. Logistical difficulties precluded the use of random sampling of animals in the province and over the seasons, so prevalence values cannot be assumed to be an accurate estimate of prevalence across each entire province due to potential selection bias. In addition, the

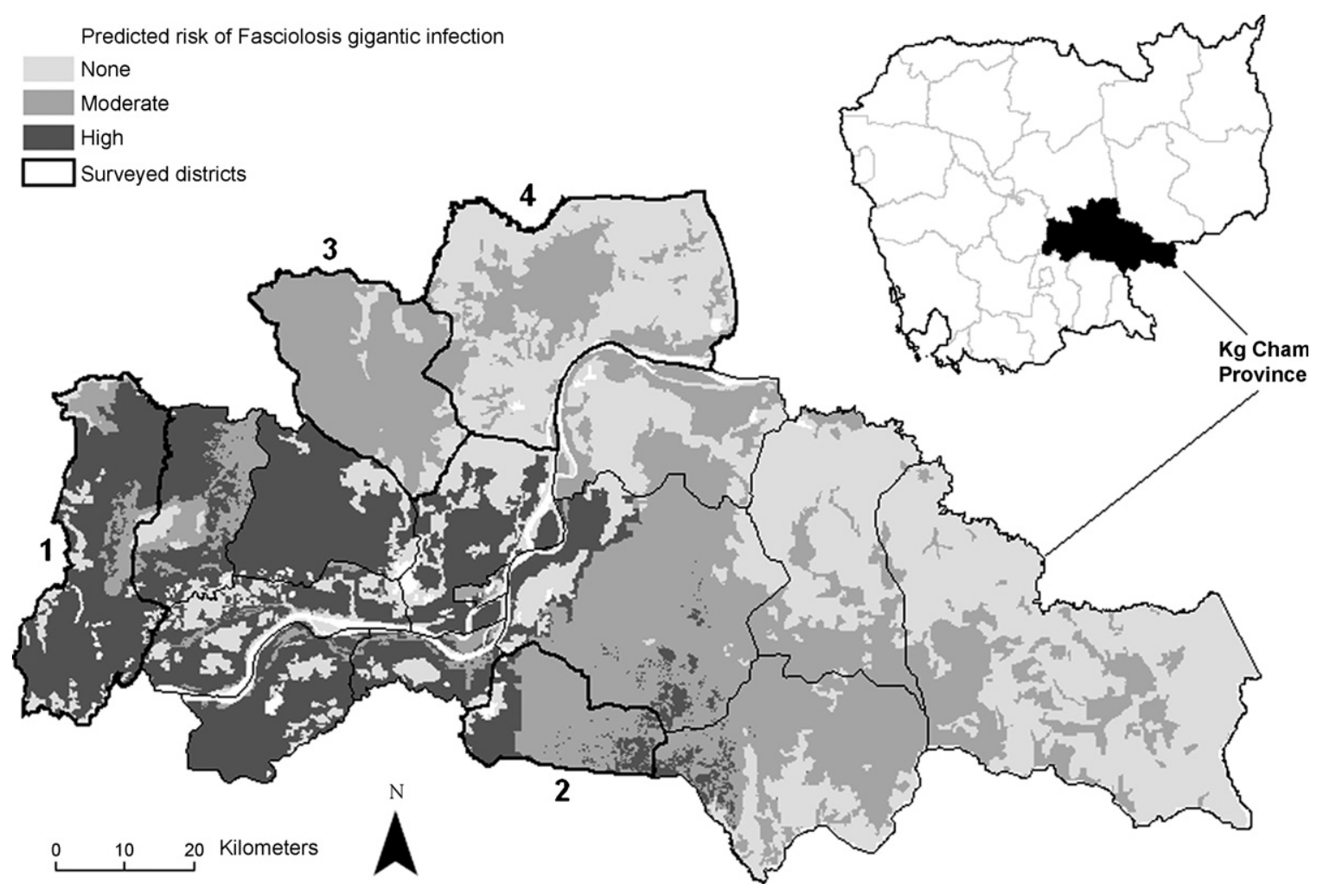

Fig. 1. The risk of transmission of fasciolosis due to Fasciola gigantica (adjusted by animal density) as predicted by the GIS model developed by Tum et al. (2004) for $\mathrm{Kg}$. Cham province and the four districts that were surveyed for prevalence of fasciolosis in cattle to test the model. 
Table 2

Results of faecal examination from different districts in 2004 within the province Kg. Cham and predicted risk of fasciolosis from GIS model (Tum et al., 2004) generalised by district and adjusted for the known sensitivity of the technique as per Anderson et al. (1999)

\begin{tabular}{llll}
\hline District & Sample size & Percent positive (95\% C.L.) & Predicted risk \\
\hline 1. Baatheay & 387 & $29.4(23.8-35.7)$ & High \\
2. Ou Reang Ov and 3. Chamkaar Leu & 286 & $9.4(5.9-14.2)$ & Moderate \\
4. Stoeung Trang & 271 & $5.0(2.5-8.9)$ & None \\
\hline
\end{tabular}

egg counting technique is insensitive to low egg counts, cyclical production of eggs by adult worms and infection with immature stages and should be regarded as an index of infection rather than as a gold standard to determine prevalence (Anderson et al., 1999).

Additional fieldwork was carried out in December and January 2004 to measure prevalence at a finer spatial scale (at the district rather than the provincial level) for a much smaller geographic region (a single province rather than the many provinces sampled earlier). The Kg. Cham province (Fig. 1) was chosen because the risk model predicted a range of levels of risk across its districts, it is located relatively close to Phnom Penh, and it was logistically feasible to conduct a census of individual animals as well as measure prevalence for four districts (1, Baatheay; 2, Ou Reang Ov; 3, Chamkaar Leu; 4, Stoeung Trang). Conducting the census enabled the random selection of animals (from a numerical listing) across the four districts examined, from which 831 faecal samples were collected and analysed using a modified version of the Balivet egg count technique, adjusted for the known sensitivity of the technique (as per Anderson et al., 1999) (Table 2). These samples were spread across three categories of predicted risk of fasciolosis: high $(n=311)$, moderate $(n=268)$ and none $(n=262)$. Of the samples, 103 out of 801 tested positive for Fasciola eggs. The highest prevalence of fasciolosis was found in the Baatheay district (29.4\%), followed by Chamcar Leu and Orang Ov (9.4\%), and Stoeung Trang (5.0\%), compared to the estimate of $6.3 \%$ (Table 1) completed in 2001 for the province as a whole. As with the original field survey, the highest prevalence is found in the area predicted to have the highest risk (Baatheay). However, a prevalence of $5.0 \%$ was found in the area predicted to have no risk. This is likely due to factors as yet unresolved by the model. Most obviously, cattle and buffalo sampled in the no-risk district may feed across a wider geographic area (especially when feed is scarce), thus occasionally visiting a risk area even if most time is spent where no risk is predicted. This is exacerbated in Stoeung Trang, as high and moderate risk areas are located nearby. A future version of the model could take this into account even in the absence of detailed mapping of animal movement patterns by assuming that no-risk areas located within a reasonable distance of high-risk areas would sustain some level of risk. Also contributing to this is that the no-risk district is located close enough to the river for farmers to irrigate rice crops which could enable the spread of fasciolosis. The development of a GIS dataset showing the location of irrigated areas would allow this to be taken into account. This present inability to distinguish areas of no risk is not a significant issue because control efforts for fasciolosis will be initially concentrated in areas of high risk (which appear to be well resolved by the model, and further validation and refinement of the model will occur as these efforts are undertaken. Finally, while the surveys were not conducted in the same year (2001/ 2002 versus 2004), they were conducted at the same time of year (start of the dry season when the prevalence of fasciolosis starts to increase), which is likely to be more important to the prevalence of fasciolosis (and no control efforts were undertaken between 2002 and 2004). Overall, the risk model developed by Tum et al., 2004 appears to provide a valuable tool to help the Department of Animal Production and Health in the Kingdom of Cambodia to identify districts of high risk in which to target control programs for fasciolosis.

\section{Acknowledgements}

The Australian Center for International Agricultural Research (ACIAR) provided financial support for this study. Staff of the Department of Animal Health and Production, Phnom Penh, and the Office of Animal Health and Production, Kampong Cham, Cambodia provided valuable assistance in collecting and analysing samples.

\section{References}

Anderson, N., Luong, T., Vo, N., Bui, K., Smooker, P., Spithill, T., 1999. The sensitivity and specificity of two methods for detecting Fasciola infections in cattle. Vet. Parasitol. 83, 15-24. 
Malone, J.B., 1994. The landscape epidemiology of fasciolosis: geographic determinants of disease risk. In: Boray, J.C. (Ed.), Immunology, pathobiology and control of fasciolosis. Round table conference at the VIIIth International Congress on Parasitology, Izmir, Turkey. Merck AgVet, Rahway, New Jersey, pp. 65-81.

Malone, J.B., Yilma, J.M., 1999. Predicting outbreaks of fasciolosis: from Ollerenshaw to satellites. In: Dalton, J.P. (Ed.), Fasciolosis. CAB International, pp. 151-1831.

Roberts, J.A., Suhardono, D., 1996. Approaches to the control of fasciolosis in ruminants. Int. J. Parasitol. 26, 971-981.

Spithill, T.W., Smooker, P.M., Copeman, D.B., 1999. Fasciola gigantica: epidemiology, control, immunology and molecular biology.
In: Dalton, J.P. (Ed.), Fasciolosis. CAB International, pp. 465524.

Suhardono, D., Copeman, D.B., 2000. Population dynamics of snail Lymnaea rubiginosa in rice fields and its infection with larvae of trematodes in the subdistrict of Surade, West Java. J. Ilmu Ternak dan Vet. 5, 241-249.

Tembely, S., Galvin, T.J., Craig, T.M., Traore, S., 1988. Liver fluke infections of cattle in Mali. An abattoir survey on prevalence and geographic distribution. Trop. Anim. Health Prod. 20, 117-121.

Tum, S., Puotinen, M.L., Copeman, B.D., 2004. Using geographic information systems (GIS) to map the risk of Fasciolosis gigantica in Cambodia. Vet. Parasitol. 122 (2), 141-149. 